\title{
Creatine-creatine phosphate shuttle modeled as two-compartment system at different levels of creatine kinase activity
}

\author{
Sergey N. Fedosov * \\ Department of Chemistry, Physical Chemistry Division, Aarhus University, DK-8000 Aarhus C, Denmark
}

Received 3 November 1993

\begin{abstract}
In order to characterize ADP-ATP and creatine-creatine phosphate ( $\mathrm{Cr}$ - $\mathrm{CrP})$ shuttles a minimal mathematical model with two compartments and cyclic turnover of matter was designed. The 'mitochondrial' compartment contained 'ATP-synthase' and 'mitochondrial creatine kinase' (mitCK). The 'cytoplasmic' compartment consisted of 'ATPase', 'cytoplasmic creatine kinase' (cytCK) and an 'ADP-binding structure'. The exchange of metabolites between these compartments was limited. Different levels of cytCK and mitCK expression as well as different exchange rate constants between the compartments were assigned to obtain several different modes. Every steady state obtained in the presence of low ATPase activity ('resting' conditions) was then disturbed by a steep activation of ATPase ('muscle performance') and afterwards the transition to a new steady state was followed in time. The ATP-buffering capacity of the system initially acquired by cytCK expression significantly increased after additional mitCK supplement. Nevertheless, even the complete $\mathrm{Cr}-\mathrm{CrP}$ shuttle failed to maintain a high [ATP]/[ADP] ratio during long term 'muscle performance' due to the rate limiting CK-transphosphorylation in the mitochondria. The facilitated diffusion of $\mathrm{Cr}$ and $\mathrm{CrP}$ was not critical, and the model worked with the same efficiency even at equal permeabilities for nucleotides and guanidines. Under 'resting conditions' the main flux of matter went through the Cr-CrP shuttle, resulting in 'pumping' of $\mathrm{CrP}$. This ensured a $40 \mathrm{~s}$ delay in the [ATP] decrease at 'work'. The partial systems without mitCK were not as effective, and this delay was 0-10 s. However, the ADP-ATP shuttle was of more importance at the steady state achieved under 'working' conditions.
\end{abstract}

Keywords: Creatine; Modeling; NMR; Enzyme kinetics

\section{Introduction}

Creatine kinase (CK) is a key enzyme for high energy phosphate metabolism. It catalyzes the reversible transfer of a phosphoryl group from creatine phosphate $(\mathrm{CrP})$ to ADP to form ATP. The abundance of CrP and cytoplasmic CK activity ensure the effective buffering of the ATP pool. The second important function of CK is energy transmission from mitochondria to the places of its utilization [1-3]. The spatially separated isoenzymes of CK catalyze the reaction $\mathrm{CrP}+\mathrm{ADP} \rightleftharpoons \mathrm{Cr}+\mathrm{ATP}$ in the mitochondrial and cytoplasmic compartments. $\mathrm{Cr}$ and $\mathrm{CrP}$ circulate between these compartments due to higher diffusion permeability of guanidines relative to that of adenine nucleotides

\footnotetext{
Abbreviations: $\mathrm{CK}$, creatine kinase; $\mathrm{CrP}$, creatine phosphate; $\mathrm{Cr}$, creatine; NMR, nuclear magnetic resonance; GPA, $\beta$-guanidinopropionic acid.

* Corresponding author. Fax: +4586196199.
}

$[3,4]$. This is a, albeit brief, description of the generally accepted physiological role of $\mathrm{CK}$.

It is difficult to define, however, the rank of the CKsystem among the other ATP-synthesizing systems according to their importance. Recent nuclear magnetic resonance (NMR) studies of CrP-ATP interconversion in vivo gave contradictory results [5-10]. The most surprising was that reported by Shoubridge and Radda [6,7]. Using a special diet for rats (6-10 weeks) they substituted $\mathrm{Cr}$ with its analog $\beta$-guanidinopropionic acid (GPA) which was slowly converted by $\mathrm{CK}$. The purpose was to suppress the fast $\mathrm{ATP} \rightleftharpoons \mathrm{CrP}$ transphosphorylation and break the $\mathrm{Cr}-\mathrm{CrP}$ shuttle, leaving the muscle with only the ADP-ATP shuttle. No significant difference was observed in muscle twitch force and in the [ATP] time-course between the control and GPA-fed animals during muscle contraction for $60 \mathrm{~min}$. The authors concluded, therefore, that $\mathrm{CrP}$ and CKs are not important for ATP buffering at aerobic metabolism [7]. In similar experiments performed by Meyer 
et al. [10] an advantage of the control animals above the GPA-fed group in muscles isometric twitch force during the first $100 \mathrm{~s}$ of contraction was observed. The GPA-experiments, however, did not rule out the time-dependent adaptation, thus precluding a direct interpretation. It seems to be difficult to separate the consequences of a disturbance in the CK-system from the other compensatory changes in different branches of the ATP metabolism.

Another approach to the problem arose from mathematical modeling of the reaction system itself. The importance of the $\mathrm{CrP}$ buffering function was confirmed by modeling of a one-compartment system with two CK-reactions being in equilibrium [11]. In the present study model calculations were made, taking into account the individual properties of the enzymes present in different compartments. The attention was focused on the following questions: (i) Does the buffering capacity of the CK-system depend on the presence of mitochondrial CK? (ii) Is the $\mathrm{Cr}$-CrP shuttle competent to retain a high ATP level during long-term intensive muscle performance? (iii) What is the effect of diffusion restrictions enforced on the $\mathrm{Cr}-\mathrm{CrP}$ and $\mathrm{ADP}-\mathrm{ATP}$ shuttles?

\section{The model}

The general scheme is shown in Fig. 1 (for more detail see expanded schemes for the individual enzymes and the set of differential equations in the Appendix).

The choice of rate constants is shown in Table 1. They are based on the following considerations.
Table 1

The set of rate constants used in the model, see Fig.1 and schemes of enzymatic reactions in the Appendix

\begin{tabular}{lrlr}
\hline Kinetic constant & Value $\left(\mathrm{s}^{-1}\right)$ & Kinetic constant & Value $\left(\mathrm{s}^{-1}\right)$ \\
\hline$k_{+1}$ & 10000 & $k_{+11}$ & 10000 \\
$k_{-1}$ & 100 & $k_{-11}$ & 500 \\
$k_{+2}$ & 100000 & $k_{+12}$ & 10000 \\
$k_{-2}$ & 5 & $k_{-12}$ & 30000 \\
$k_{+3}$ & 25 & $k_{+13}$ & 100000000 \\
$k_{+4}$ & 100 & $k_{-13}$ & 120 \\
$k_{-4}$ & 1 & $k_{+14}$ & 10000000 \\
$k_{+5}$ & 10000 & $k_{-14}$ & 360 \\
$k_{-5}$ & 1000 & $k_{+15}$ & 100 \\
$k_{+6}$, rest & 1 & $k_{-15}$ & 30 \\
$k_{+6}$, work & 10 & $k_{+16}$ & 1000 \\
$k_{+7}$ & 10000 & $k_{-16}$ & 10 \\
$k_{-7}$ & 200 & $k_{+17}$ & 1000 \\
$k_{+8}$ & 100 & $k_{-17}$ & 10 \\
$k_{-8}$ & 1 & & \\
$k_{+9}$ & 1000 & & \\
$k_{-9}$ & 10 & & \\
$k_{+10}$ & 100 & & \\
$k_{-10}$ & 60 & & \\
\hline Value: $k_{+i}(1,2,5,7)$ in $\mathrm{mM}^{-1} \mathrm{~s}^{-1} ; k_{+i}(11,12,13,14) \mathrm{in} \mathrm{mM}^{-2} \mathrm{~s}^{-1}$
\end{tabular}

\subsection{Exchange of metabolites between the 'mitochondrial' and the 'cytoplasmic' compartments}

Let us begin with a simple example to clarify the features of the two compartment system modeling. There are two compartments: mitochondrial and cytoplasmic which exchange metabolites but not protein. Their volumes are $0.01 v$ and $v$, respectively. If 101 metabolite molecules

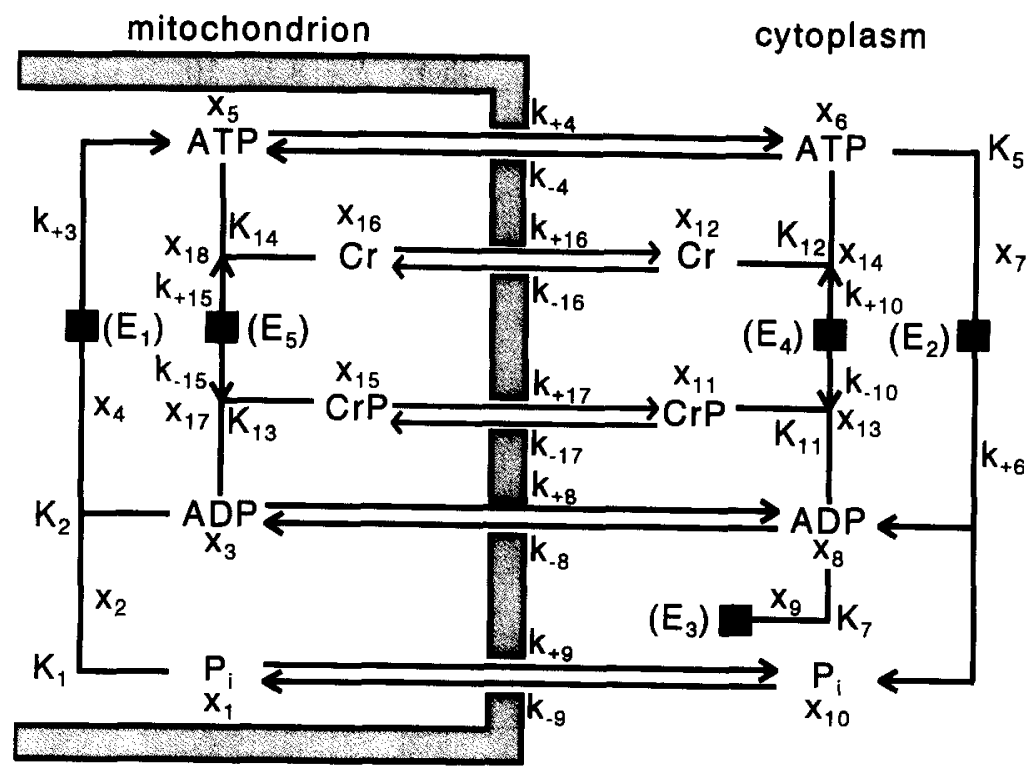

Fig. 1. General scheme of the ADP-ATP and Cr-CrP shuttles. $E_{1}$, ATP synthase; $E_{2}, A T P a s e ; E_{3}, A D P$ binding subcellular structure; $E_{4}$, cytoplasmic CK; $\mathrm{E}_{5}$, mitochondrial CK. For more detail see extended schemes of the enzymatic reactions in the Appendix. 
are added to the cytoplasmic pool, the equilibrium distribution of the metabolite will be: 1 molecule in the mitochondrial compartment and 100 molecules in the cytoplasmic one, whereas the concentrations ( 100 metabolite molecules per volume $v$ ) are the same in both pools.

The equation for the proposed exchange process is at equilibrium:

$N_{\text {mit }} k_{\text {out }}=N_{\text {cyt }} k_{\text {in }} \quad\left(N_{\text {mit }}^{\stackrel{\text { out }}{\rightleftharpoons}} N_{\text {cyt }}\right)$

where $N_{i}$ is the number of moles in corresponding compartment and the rate constants $k_{\text {out }}, k_{\text {in }}$ have the ratio $\left(k_{\text {out }} / k_{\text {in }}\right)=100$. This equation could be also written using concentrations $C_{i}$ and volumes $v$ :

$C_{\text {mit }} 0.01 v k_{\text {out }}=C_{\text {cyt }} v k_{\text {in }}$

Then, after assignment $C_{\mathrm{mit}}^{*}=0.01 C_{\mathrm{mit}}$, we have the final equation:

$C_{\text {mit }}^{*} k_{\text {out }}=C_{\text {cyt }} k_{\text {in }}$

where the apparent concentration in the mitochondrial compartment $C_{\text {mit }}^{*}$ is $1 / 100$ of the real concentration $C_{\text {mit }}$. This procedure then requires a corresponding reduction (1:100) of all metabolite dissociation constants for mitochondrial proteins.

The metabolite transition from one compartment to another is assumed to be the limiting step in the diffusion. The strict description requires several additional parameters; e.g., comparison of the diffusion itself with the permeability through the membrane. Such data are now rather incomplete and therefore the metabolite transition was described as a one-step process controlled by the 'exchange' (or 'diffusion') rate constants.

The absolute values of the exchange constants were arrived at by trial and error, such that the model simulates the behavior of a muscle cell reasonably well. The $\mathrm{Cr}, \mathrm{CrP}$ and $P_{i}$ permeabilities were assigned as relatively 'facilitated', being 10-times higher than those for ATP and ADP. These arbitrary values were then subject to variation in order to reveal the effects of diffusion on the system.

\subsection{Kinetic characteristics of the mitochondrial enzymes}

Two enzymes ATP-synthase $\left(E_{1}\right)$ and mitochondrial CK $\left(E_{5}\right)$ were present in the mitochondrial compartment. The whole ATP-producing system was denoted as a single enzyme $E_{1}$. Therefore, the corresponding rate constants are apparent, being functions of the oxidative phosphorylation process.

The constant values were chosen on the basis of the literature $[2,3,12-20]$. Relatively fast substrate binding and release ( $E+S \rightleftharpoons E S$ ) were assumed, compared to the rate of catalysis. A possible interpretation of some of the rate constants is as follows: $k_{-1} / k_{+1} \approx 0.01 K_{\mathrm{m}}\left(\mathrm{P}_{\mathrm{i}}\right)$ and $\left(k_{-2}\right.$ $\left.+k_{+3}\right) / k_{+2} \approx 0.01 K_{\mathrm{m}}(\mathrm{ADP})$ for $\mathrm{E}_{1} ; k_{-13} / k_{+13} \approx$ $K_{\mathrm{s}}(\mathrm{ADP}) K_{\mathrm{m}}(\mathrm{CrP}) \cdot 10^{-4}$ and $k_{-14} / k_{+14} \approx K_{\mathrm{s}}$
(ATP) $K_{\mathrm{m}}(\mathrm{Cr}) \cdot 10^{-4}$ for $\mathrm{E}_{5}$. All apparent $K_{\mathrm{s}}$ and $K_{\mathrm{m}}$ values for the mitochondrial enzymes in the model were reduced by a factor of 100 to compensate for the difference in the compartment volumes.

\subsection{The features of the cytoplasmic enzymes}

Three proteins are present in the cytoplasmic compartment in the scheme: ATPase ( $\left.\mathrm{E}_{2}\right)$, ADP-binding structure $\left(E_{3}\right)$ and cytoplasmic $C K\left(E_{4}\right)$. The values of the constants were chosen on the basis of the literature [2-4,19-26]. An interpretation of some of the rate constants is the following: $k_{-5} / k_{+5} \approx K_{\mathrm{m}}(\mathrm{ATP})$ for $\mathrm{E}_{2} ; k_{-7} / k_{+7} \approx K_{\mathrm{s}}(\mathrm{ADP})$ for $\mathrm{E}_{3} ; k_{-11} / k_{+11} \approx K_{\mathrm{s}}(\mathrm{ADP}) K_{\mathrm{m}}(\mathrm{CrP})$ and $k_{-12} / k_{+12} \approx$ $K_{\mathrm{s}}(\mathrm{ATP}) K_{\mathrm{m}}(\mathrm{Cr})$ for $\mathrm{E}_{4}$.

\subsection{Protein concentrations}

Concentrations of substrate binding sites in the proteins were assigned to be: $\left[\mathrm{E}_{1}\right]=0.1 \mathrm{mM}$ (ATP-synthase), $\left[\mathrm{E}_{2}\right]$ $=0.1 \mathrm{mM}$ (ATPase), $\left[\mathrm{E}_{3}\right]=0.2 \mathrm{mM}$ (ADP-binding subcellular structure), $\left[\mathrm{E}_{4}\right]=0.1 \mathrm{mM}$ (cytoplasmic $\mathrm{CK}$ ), $\left[\mathrm{E}_{5}\right]$ $=0.02 \mathrm{mM}$ (mitochondrial $\mathrm{CK}$ ). The values of $\left[\mathrm{E}_{4}\right]$ and $\left[\mathrm{E}_{5}\right]$ were varied in the calculations to compare the behavior of the system at different levels of CK activity.

All concentrations in the model were calculated per liter of the cytoplasmic compartment volume $(v)$, which is approximately equal to the total volume of the system $(1.01 v)$

\subsection{Free energy of ATP hydrolysis}

The values were calculated according to the equation:

$\Delta G=\Delta G^{\circ}-R T \ln \frac{[\mathrm{ATP}]}{[\mathrm{ADP}]\left[\mathrm{P}_{\mathrm{i}}\right]}$

where $R=8.31 \cdot 10^{-3} \mathrm{~kJ} / \mathrm{mol} \mathrm{K}, T=310 \mathrm{~K}, \Delta G^{\circ}=$ $-30.5 \mathrm{~kJ} / \mathrm{mol}$. The value of $\Delta G$ cannot be strictly interpreted as free energy at transition from one steady state to another (see below Fig. 4). Nevertheless, it could be useful for the $[\mathrm{ATP}] /[\mathrm{ADP}]\left[\mathrm{P}_{\mathrm{i}}\right]$ ratio estimates.

\subsection{Calculations}

Calculations were done using a system of differential equations (see the Appendix) and the algorithm of Runge-Kutta in Feldberg's modification. The program (S.N. Fedosov, unpublished) was installed on an IBM PC AT computer.

\section{Results}

The analysis of the scheme was performed through several steps (modes), going from a partial scheme to the 
most complex one. These steps (modes $1-5$ ) reflected the sequence of protein expression in the embryonic and evolutionary development. In the simplest mode 1 , only three proteins were present: $\mathrm{E}_{1}$ (ATP-synthase), $\mathrm{E}_{2}$ (ATPase) and $E_{3}$ (ATP-binding structure). Further development of the system was achieved in modes 2 and 3 step by step through a gain of $\mathrm{E}_{4}$ (cytoplasmic CK). The network was completed in modes 4 and 5 after $\mathrm{E}_{5}$ (mitochondrial $\mathrm{CK}$ ) expression. Steady state concentrations of the metabolites were calculated for the system at 'rest' at low $\mathrm{E}_{2}$ activity (ATPase). Steep activation of the ATPase disturbed the 'resting system' and the transition to a new steady state for ATP, CrP and the other metabolites was followed in time. Comparison of the results from modes $1-5$ revealed the role of the different components in the model to maintain a high ATP concentration in the cytoplasmic compartment. Low and high exchange rates between the compartments showed the possible effect of diffusion on ATP turnover.

\section{1. 'Resting system': steady-state concentrations of metabolites}

To obtain the steady state concentrations for all intermediates $\left(X_{1}, \ldots, X_{18}\right)$ in modes $1-5$ the starting values of the variables were set to zero except $X_{6}(\mathrm{ATP})=5 \mathrm{mM}$, $X_{10}\left(\mathrm{P}_{\mathrm{i}}\right)=2 \mathrm{mM}$ and $X_{11}(\mathrm{CrP})+X_{12}(\mathrm{Cr})=40 \mathrm{mM}$. The ratio $X_{11} / X_{12}$ varied from mode 1 to mode 5 to bring the steady state $P_{i}$ concentration to $\approx 2 \mathrm{mM}$ which is known for the resting muscle $[3,4,6,7]$. The steady state concentrations of cytoplasmic metabolites at 'rest' were obtained after several iterations, going from initial $X_{1}, \ldots, X_{18}$ values, and are presented in Table 2.

The metabolite ratio $[\mathrm{M}]_{\mathrm{mit}} /[\mathrm{M}]_{\mathrm{cyt}}$ for $\mathrm{Cr}, \mathrm{CrP}, \mathrm{P}_{\mathrm{i}}$ and ATP in the mitochondrial and cytoplasmic compartments were approximately equal to the ratio of the exchange rate constants $k_{\text {in }} / k_{\text {out }}=0.01$ in all modes because of the fast exchange between the two pools. The concentration of mitochondrial ADP was everywhere $\approx 2 \cdot 10^{-5} \mathrm{mM}$ which corresponds to $2 \cdot 10^{-3} \mathrm{mM}$ inside the real mitochondrial compartment. The total circulating flux of the matter in the network was $\approx 0.098 \mathrm{mM} \mathrm{s}^{-1}$.

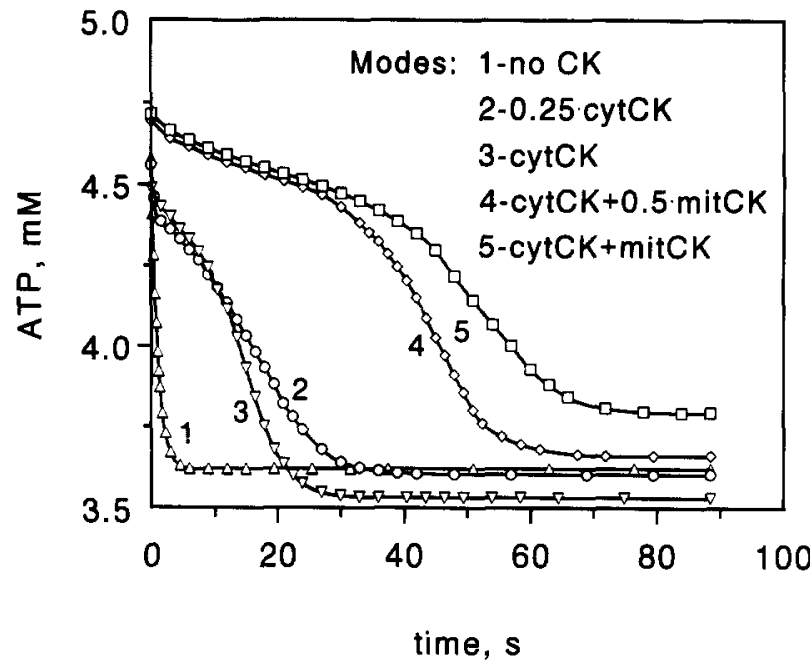

Fig. 2. Changes in the cytoplasmic ATP concentration traced after the ATPase $\left(E_{2}\right)$ activation.

\section{2. 'Working system': Time dependence of metabolite concentrations}

Imitation of the muscle performance in the model was achieved by a steep activation of ATPase $\left(\mathrm{E}_{2}, k_{+6}=10\right.$ $\mathrm{s}^{-1}$ ). Steady states obtained for the modes $1-5$ in the previous section were disturbed in this way and the changes in metabolite concentrations were followed in time.

The time dependence for free cytoplasmic ATP, CrP concentrations and $\Delta G$ are presented in Figs. 2-4. The new steady state concentrations of the cytoplasmic metabolites are shown in Table 3. $\mathrm{Cr}, \mathrm{CrP}$ and $\mathrm{P}_{\mathrm{i}}$ were again in relatively fast exchange between the compartments according to the ratio $[\mathrm{M}]_{\mathrm{mit}} /[\mathrm{M}]_{\mathrm{cyt}} \approx 0.01$. The concentration of mitochondrial ADP in all modes was $\approx 2 \cdot 10^{-4} \mathrm{mM}$ (i.e., $2 \cdot 10^{-2} \mathrm{mM}$ in the real system). The total circulating flux of the matter in the network was $\approx 0.97 \mathrm{mM} \mathrm{s}^{-1}$.

It should be emphasized that the CK reaction in the cytoplasm was almost in equilibrium both in the 'resting' and in the 'working' systems: $K_{\mathrm{eq}}^{\mathrm{app}}=[\mathrm{CrP}][\mathrm{ADP}] /$ $[\mathrm{Cr}][\mathrm{ATP}]=0.01$ at neutral $\mathrm{pH}[20]$. This is definitely not the case for the mitochondrial $\mathrm{CK}$ according to the substrate ratios in mitochondrial compartment.

Table 2

Cytoplasmic metabolites steady state concentrations in the 'resting system'

\begin{tabular}{|c|c|c|c|c|c|}
\hline \multirow{2}{*}{$\begin{array}{l}\text { Free } \\
\text { cytoplasmic } \\
\text { metabolite }\end{array}$} & \multicolumn{5}{|c|}{ Concentration (mM) } \\
\hline & $\begin{array}{l}\text { Mode } 1, \\
E_{4}=0 \\
E_{5}=0\end{array}$ & $\begin{array}{l}\text { Mode } 2 \\
\mathrm{E}_{4}=25 \% \\
\mathrm{E}_{5}=0\end{array}$ & $\begin{array}{l}\text { Mode } 3 \\
\mathrm{E}_{4}=100 \% \\
\mathrm{E}_{5}=0\end{array}$ & $\begin{array}{l}\text { Mode } 4 \\
E_{4}=100 \%, \\
E_{5}=50 \%\end{array}$ & $\begin{array}{l}\text { Mode } 5 \\
E_{4}=100 \%, \\
E_{5}=100 \%\end{array}$ \\
\hline ATP & 4.58 & 4.56 & 4.49 & 4.69 & 4.71 \\
\hline ADP & 0.0997 & 0.0998 & 0.0997 & 0.00639 & 0.00317 \\
\hline$P_{i}$ & 2.18 & 1.94 & 1.92 & 1.92 & 1.92 \\
\hline $\mathrm{CrP}$ & - & 12.4 & 12.3 & 34.9 & 37.1 \\
\hline $\mathrm{Cr}$ & - & 27.2 & 27.2 & 4.60 & 2.41 \\
\hline Flux $J, \mathrm{mM} / \mathrm{s}$ & 0.0979 & 0.0979 & 0.0978 & 0.0979 & 0.0979 \\
\hline$\Delta G, \mathrm{ATP}, \mathrm{kJ} / \mathrm{mol}$ & -56 & -56 & -56 & -63 & -65 \\
\hline
\end{tabular}




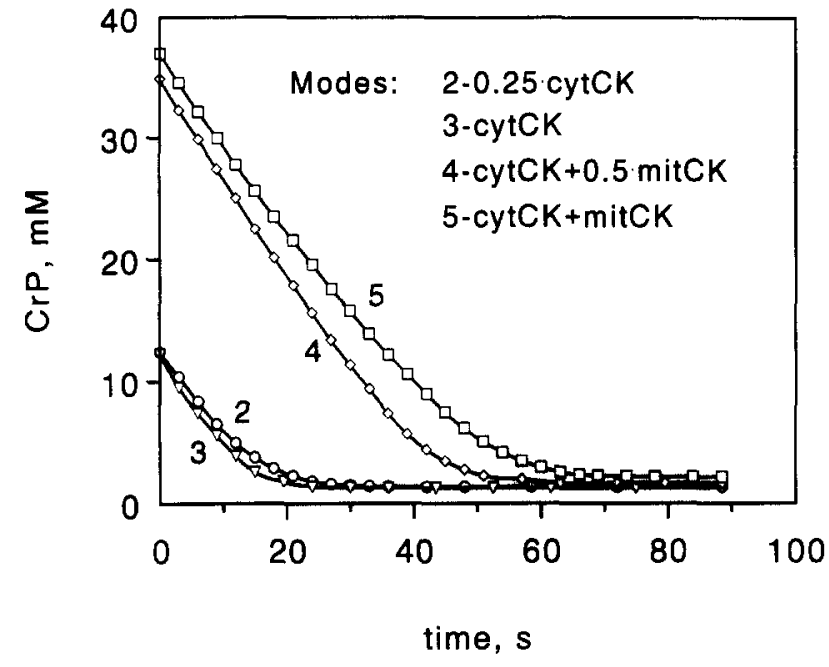

Fig. 3. Changes in the cytoplasmic $\mathrm{CrP}$ concentration traced after the ATPase $\left(E_{2}\right)$ activation.

\subsection{Variations in diffusion constants}

For the previous calculations the exchange rate constants for $\mathrm{Cr}, \mathrm{Cr} P$ and $\mathrm{P}_{i}$ were assumed to be relatively high. They were one order of magnitude higher than those for ATP and ADP which are supposed to be limited in diffusion [11] and especially in mitochondrial membrane permeability [4]. In the following simulations the sensitivity of the model to the variations in the exchange rate constants was investigated. The ADP constants were taken as minimal as this metabolite is believed to be the most diffusion restricted species in the ADP-ATP and $\mathrm{Cr}-\mathrm{CrP}$ shuttles $[3,4]$. The constants for the other metabolites were assigned equal or 10 times higher than those for ADP, keeping the ratio $k_{\text {in }} / k_{\text {out }}=0.01$ constant. The question to be addressed includes the correlation between the changes in diffusion constants and the concentrations of ATP and $\mathrm{CrP}$ in the cytoplasmic pool.

'Facilitation' of ATP diffusion in mode 1 with only the ADP-ATP shuttle did not change cytoplasmic metabolites concentrations (not shown). Neither did the equal permeability enforced on ATP, ADP and $P_{i}$. All these facts pointed to the low sensitivity of the system to the varia-

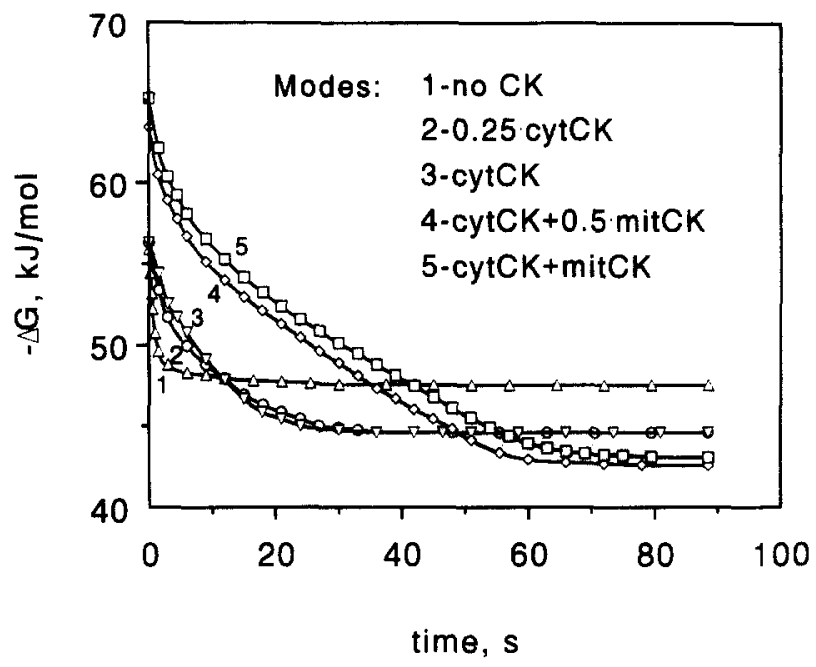

Fig. 4. Changes in $\Delta G$ traced after the ATPase $\left(\mathrm{E}_{2}\right)$ activation.

tions in ATP and $P_{i}$ diffusion rate constants when they are equal or higher than those for ADP.

When the system of two interacting shuttles (mode 5) was left with only $P_{i}$ having preference in the diffusion, no significant difference in cytoplasmic metabolite concentrations was revealed. Even diffusion restrictions enforced on $P_{i}$ (equal permeabilities for all metabolites) did not disturb the concentration time-courses in the cytoplasmic compartment. Thus, the same conclusion was reached: the relative variations in exchange rate constants for the metabolites are not crucial for the behavior of the system when they do not cross the low limit determined by the ADP exchange rate constants. In all modes, significant differences were observed only in the intramitochondrial metabolite concentrations necessary to counterbalance the changes in rate constants, and to ensure appropriate input and output fluxes.

The second factor under consideration was the diffusion distance for metabolites. The exchange between the two compartments was previously assigned as 'moderate'. The lowest exchange rate constants were those for ADP: 100 $\mathrm{s}^{-1}$ and $1 \mathrm{~s}^{-1}$. All the others were related to the ADP rate constants. Here all diffusion constants $\left(k_{\text {diff }}\right)$ in modes 1 and 5 were changed in parallel and their values were

Table 3

Cytoplasmic metabolites steady state concentrations in the 'working system'

\begin{tabular}{|c|c|c|c|c|c|}
\hline \multirow{2}{*}{$\begin{array}{l}\text { Free } \\
\text { cytoplasmic } \\
\text { metabolite }\end{array}$} & \multicolumn{5}{|c|}{ Concentration (mM) } \\
\hline & $\begin{array}{l}\text { Mode } 1 \\
\mathrm{E}_{4}=0 \\
\mathrm{E}_{5}=0\end{array}$ & $\begin{array}{l}\text { Mode } 2 \\
\mathrm{E}_{4}=25 \% \\
\mathrm{E}_{5}=0\end{array}$ & $\begin{array}{l}\text { Mode } 3, \\
E_{4}=100 \%, \\
E_{5}=0\end{array}$ & $\begin{array}{l}\text { Mode } 4 \\
\mathrm{E}_{4}=100 \%, \\
\mathrm{E}_{5}=50 \%\end{array}$ & $\begin{array}{l}\text { Mode } 5, \\
E_{4}=100 \%, \\
E_{5}=100 \%\end{array}$ \\
\hline ATP & 3.62 & 3.60 & 3.53 & 3.66 & 3.79 \\
\hline ADP & 1.00 & 0.993 & 0.993 & 0.852 & 0.715 \\
\hline $\mathrm{P}_{\mathrm{i}}$ & 3.12 & 13.9 & 13.8 & 36.1 & 37.7 \\
\hline $\mathrm{CrP}$ & - & 1.39 & 1.36 & 1.70 & 2.17 \\
\hline $\mathrm{Cr}$ & - & 38.2 & 38.1 & 37.8 & 37.3 \\
\hline Flux $J, \mathrm{mM} / \mathrm{s}$ & 0.973 & 0.973 & 0.972 & 0.973 & 0.974 \\
\hline$\Delta G, \mathrm{ATP}, \mathrm{kJ} / \mathrm{mol}$ & -48 & -45 & -45 & -42 & -43 \\
\hline
\end{tabular}




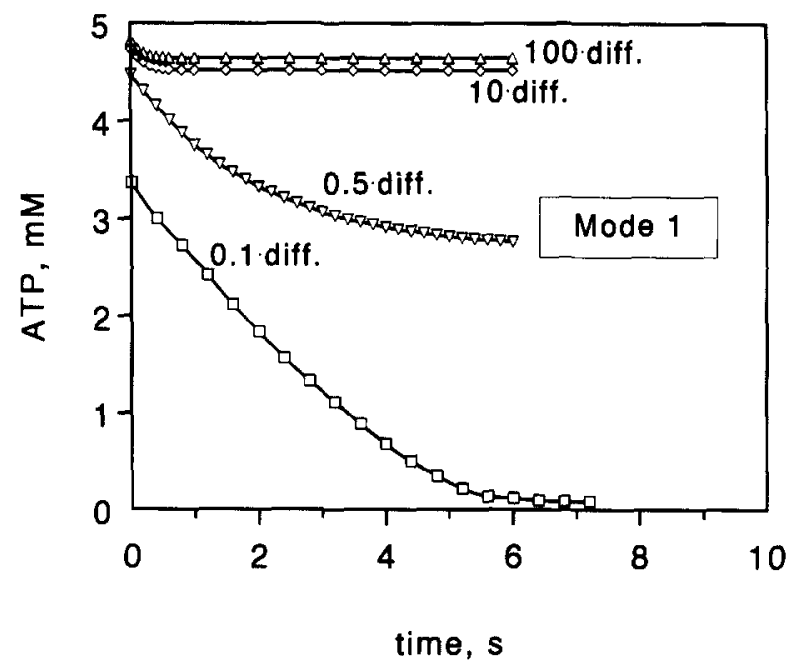

Fig. 5. Time dependence of the cytoplasmic ATP concentration traced for the system in mode 1 (ADP-ATP shuttle) after the ATPase $\left(E_{2}\right)$ activation. Different exchange rates between the compartments were enforced by multiplying the corresponding constants $\left(k_{\text {in }}\right.$ and $k_{\text {out }}$ ) by a factor of $100,10,0.5$, and 0.1 , respectively.

multiplied by the factor $100,10,0.5,0.1$. Increase or decrease in $k_{\text {diff }}$ could be interpreted as reflecting short or long diffusion distances (as well as facilitated or retarded permeabilities through the membrane) for the metabolite, respectively. The time dependence for [ATP] (Figs. 5 and 6) and $\mathrm{CrP}$ (Fig. 7) in the model undergoing transition from 'resting' to 'working' steady state were obtained.

A constant high ATP level was observed even in the absence of CKs when the diffusion distances were short $\left(100 k_{\text {diff }}\right.$ and $\left.10 k_{\text {diff }}\right)$. For instance, the cytoplasmic steady state concentrations of ATP and ADP provided by the ADP-ATP shuttle at $100 k_{\text {diff }}$ were: $4.8 \mathrm{mM}$ and $3 \mu \mathrm{M}$

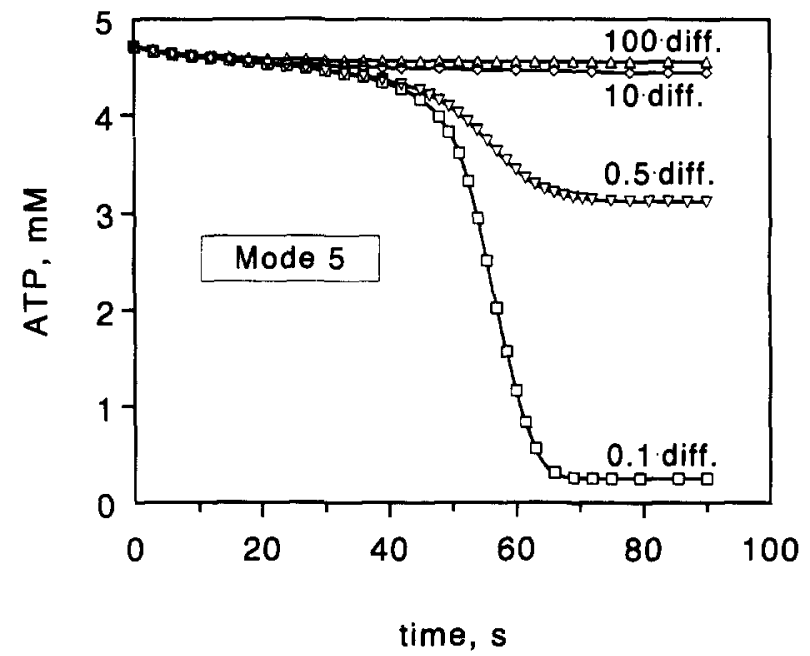

Fig. 6. Time dependence of the cytoplasmic ATP concentration traced for the system in mode 5 (ADP-ATP and $\mathrm{Cr}-\mathrm{CrP}$ shuttles) after the ATPase $\left(E_{2}\right)$ activation. Different exchange rates between the compartments were enforced by multiplying the corresponding constants $\left(k_{\text {in }}\right.$ and $\left.k_{\text {out }}\right)$ by a factor of $100,10,0.5$, and 0.1 , respectively.

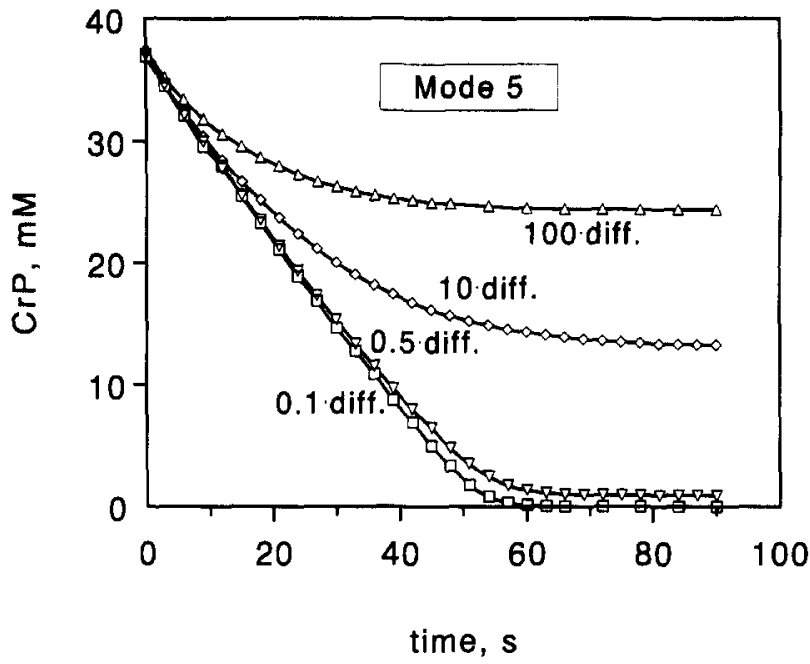

Fig. 7. Time dependence of the cytoplasmic $\mathrm{CrP}$ concentration traced for the system in mode 5 (ADP-ATP and $\mathrm{Cr}-\mathrm{CrP}$ shuttles) after the ATPase $\left(E_{2}\right)$ activation. Different exchange rates between the compartments were enforced by multiplying the corresponding constants $\left(k_{\text {in }}\right.$ and $\left.k_{\text {out }}\right)$ by a factor of $100,10,0.5$, and 0.1 , respectively.

under 'resting' conditions and $4.6 \mathrm{mM}$ and $20 \mu \mathrm{M}$ under 'working' conditions, respectively. Addition of the $\mathrm{Cr}-\mathrm{CrP}$ shuttle evoked only $\approx 25 \%$ decrease in [ADP] in comparison with the sole ADP-ATP shuttle.

A long diffusion distance $\left(0.1 k_{\text {diff }}\right)$ resulted in a significant difference between modes 1 and 5 . In the absence of CKs, high [ATP] during 'muscle performance' was no longer retained, and the total flux was $0.46 \mathrm{mM} \mathrm{s}^{-1}$ instead of the former $0.97 \mathrm{mM} \mathrm{s}^{-1}$. The system with both CKs under the same conditions held the initial ATP level for $40 \mathrm{~s}$ at the expense of previously stored $\mathrm{CrP}$. Then the ATP concentration decreased abruptly (Fig. 6.), and the total flux decreased from $0.97 \mathrm{mM} \mathrm{s}^{-1}$ to $0.72 \mathrm{mM} \mathrm{s}^{-1}$. A strong limitation in the exchange between the compartments seems unlikely because of the very low (unphysiological) ATP level finally achieved in the 'working' system.

An attempt to strongly facilitate the exchange between the pools by acceleration of $\mathrm{Cr}-\mathrm{CrP}$ diffusion did not evoke any significant response in the network, as compared with the former results. It means that the $\mathrm{Cr}$ and $\mathrm{CrP}$ permeabilities were not of great importance because these metabolites were present in high concentrations.

\section{Discussion}

The scheme considered is relatively simple with the minimal set of the parameters. Several effectors like adenylate kinase or acidification developing at muscle performance which could interfere with the calculations were omitted. However, these and other species would influence all the modes in the same way and they would thus not interfere with the comparison between modes. 
There is now a wealth of information relating the changes in concentrations of ATP, ADP, $\mathrm{CrP}$ and $\mathrm{P}_{i}$ to the time-course during skeletal muscle performance. Thus, the usual concentrations of these metabolites in resting muscle are as follows: $[\mathrm{CrP}]=20-35 \mathrm{mM},[\mathrm{Cr}]=5-10 \mathrm{mM},\left[\mathrm{P}_{i}\right]$ $=1-2 \mathrm{mM},[\mathrm{ATP}]=5-8 \mathrm{mM}$, free $[\mathrm{ADP}]=1-20 \mu \mathrm{M}$, total $[\mathrm{ADP}]=0.1-0.4 \mathrm{mM}$ (including $\mathrm{ADP}$ bound to a subcellular structures) $[3,4,6,7,22]$. The first $30-40 \mathrm{~s}$ of muscle performance are accompanied by an approximately linear decrease in $[\mathrm{CrP}]$, its relative rate being $2.4 \%$ per second [27]. [ATP] is retained constant during this time interval, and then decreases [10,27]. Finally, after 3-4 min of muscle performance only $1 / 2$ of [ATP] and $1 / 10$ of [CrP] are left $[6,7,10]$. Those levels are constant for the next $10-15 \mathrm{~min}$ and then they slowly increase $[6,7]$. The animals with suppressed $\mathrm{Cr}$-CrP shuttle lacked burst muscle activity for $\approx 1 \mathrm{~min}$ but afterwards showed a relatively increased muscle endurance $[7,8,11,28]$. It is clear that the kinetic behavior of the designed model satisfactory represents the experimental data and testifies to the validity of the model (at least for the 2 minutes of simulations).

In an attempt to elucidate the role of the mitochondrial $\mathrm{CK}$ (the latest evolutionary participant in the $\mathrm{Cr}-\mathrm{CrP}$ circuit) the energy buffering modes 1-3 and 4-5 under 'resting' conditions were compared. Attention should be called to the fact that insertion of mitochondrial CK $\left(\mathrm{E}_{5}\right)$ to the network resulted in a decrease of cytoplasmic [ADP] from $0.1 \mathrm{mM}$ (modes 1-3) to 3-6 $\mu \mathrm{M}$ (modes 4,5) but did not change significantly the intramitochondrial [ADP]. Why is it so and how does mitochondrial CK affect the ADP concentration in another compartment?

Under steady state conditions, the ATP utilization flux $\left(0.1 \mathrm{mM} \mathrm{s}^{-1}\right)$ demands a corresponding ATP synthesis. Therefore, it put requirements on the intramitochondrial [ADP] to ensure the demanded saturation of ATP-synthase. In the absence of mitochondrial CK (modes 1-3), the intramitochondrial ADP concentration is maintained by the ADP-ATP shuttle, where the influx $\mathrm{ADP}_{\mathrm{cyt}} \rightarrow \mathrm{ADP}_{\text {mit }}$ is given by $k_{-8} X_{8}-k_{8} X_{3}$. The higher the $\left[\mathrm{ADP}_{\mathrm{cyt}}\right]$ (or the exchange rate constants), the higher is the flux and vice versa. Mitochondrial $\mathrm{CK}$ adds to the ADP supply through the flux $\mathrm{Cr}_{\text {cyt }} \Rightarrow \mathrm{Cr}_{\text {mit }} \stackrel{\mathrm{CK}}{\rightarrow} \mathrm{ADP}_{\text {mit }}$. This flux is equal to $k_{-15} X_{18}-k_{15} X_{17}$ and under 'resting' conditions it satisfies $98 \%$ of the ADP needs. Therefore, the influx $\mathrm{ADP}_{\text {cyt }}$ $\rightarrow \mathrm{ADP}_{\text {mit }}$ is not very important (Fig. 8A). It allows $\left[\mathrm{ADP}_{\mathrm{cyt}}\right]$ to be low.

ADP in the cytoplasmic pool is also a substrate of the $\mathrm{CK}$ reaction. For the reaction in equilibrium the ratio $[\mathrm{ADP}] \cdot[\mathrm{CrP}] /[\mathrm{ATP}] \cdot[\mathrm{Cr}]$ is determined by $K_{\text {eq }}^{\mathrm{app}}=0.01$ for the $\mathrm{CK}$ reaction [20]. Therefore, a low ratio $[\mathrm{ADP}] /[\mathrm{ATP}]$ should be counterbalanced by high ratio $[\mathrm{CrP}] /[\mathrm{Cr}]$. Hence, the consequences of mitochondrial CK expression are low ADP and high CrP concentrations in the cytoplasm. It ensures a potentially high ATP buffering capacity of the complete system which should be much

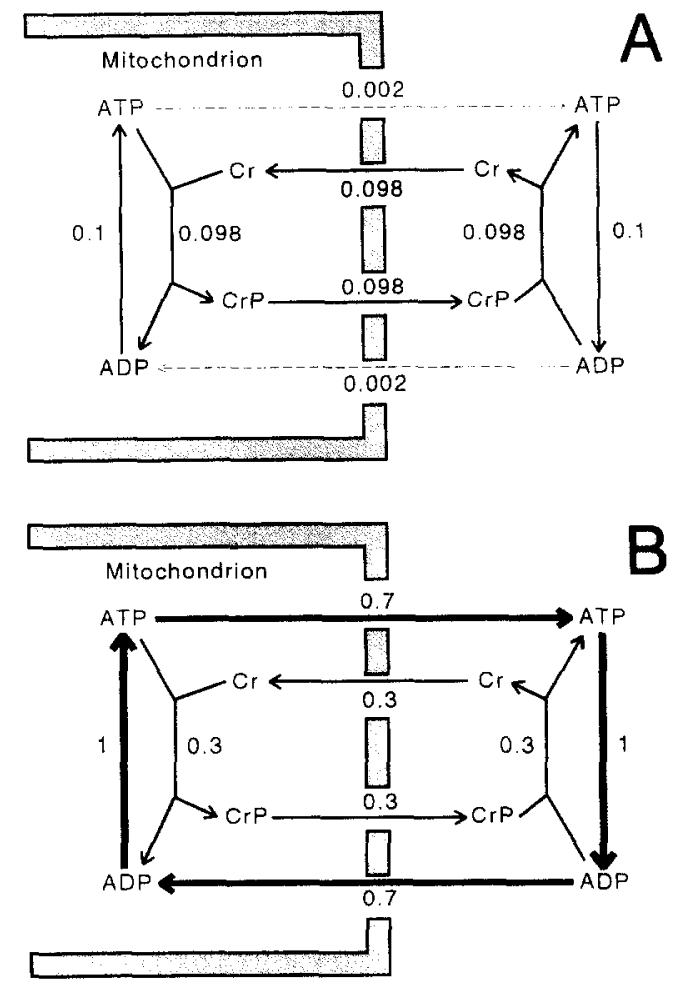

Fig. 8. Distribution of the fluxes between ADP-ATP and $\mathrm{Cr}_{-}-\mathrm{CrP}$ shuttles in mode 5 (ADP-ATP and $\mathrm{Cr}$-CrP shuttles). The values are expressed in $\mathrm{mM} \mathrm{s}^{-1}$. The thickness of the arrows reflects the magnitude of the fluxes in the different steps: (A) 'resting system', steady state; and (B) 'working system', steady state.

more pronounced than that in the presence of the sole cytoplasmic CK (compare the ratios $[\mathrm{CrP}] /[\mathrm{Cr}]$ for modes 3 and 5).

The high ATP buffering capacity of the model with mitochondrial CK (modes 4 and 5) was proved by simulation of the 'working' system. It was able to maintain the original ATP level during $40 \mathrm{~s}$ of 'muscle performance'. In the absence of mitochondrial $\mathrm{CK}$, but with the expressed cytoplasmic CK (modes 2 and 3), high [ATP] was retained only for $10 \mathrm{~s}$. Exclusion of both CKs from the network (mode 1) led to a fast decrease in [ATP] during the first 3-4 s (Fig. 2).

The $\mathrm{Cr}-\mathrm{CrP}$ shuttle, however, seemed to be incapable to maintain a high ATP concentration during long-term 'muscle performance'. Reserve $\mathrm{C}_{\mathrm{rP}} \mathrm{P}$ was exhausted during the first $40 \mathrm{~s}$, at the same time the flux through the $\mathrm{Cr}-\mathrm{CrP}$ shuttle was not sufficient to ensure the total cyclic flux of $1 \mathrm{mM} \mathrm{s}^{-1}$ (Fig. 8B). Hence, the main flux went through the ADP-ATP shuttle $\left(0.7 \mathrm{mM} \mathrm{s}^{-1}\right)$ but not through the $\mathrm{Cr}-\mathrm{CrP}$ shuttle $\left(0.3 \mathrm{mM} \mathrm{s}^{-1}\right)$ (Fig. $8 \mathrm{~B}$ ). The proportion between those flux branches could be changed in favor of the $\mathrm{Cr}-\mathrm{CrP}$ shuttle by increasing the mitochondrial $\mathrm{CK}$ concentration $\left(E_{5}\right)$. However, at high mitochondrial CK activity, the ADP concentration in the 'resting system' would be far too low, when compared to a muscle cell. 
Considering the diffusion restrictions in the network it should be emphasized that the suggested importance of a relatively high permeability for the guanidines $[3,4]$ was not confirmed in the behavior of the system. Even the low $\mathrm{Cr}$ and $\mathrm{CrP}$ permeabilities were completely compensated by their high concentrations. On the other hand, the properties of the model were very sensitive to the rate of ADP diffusion, due to its low concentration.

The system was also responsive to the changes in the concentration of the mitochondrial CK. Therefore, the individual characteristics of the mitochondrial $\mathrm{CK}$, i.e., existence of two oligomeric forms [3,29-31], different properties of the subunits [32], possible substrate tunneling [3], may influence the network notably. However, the existence of mitochondrial $\mathrm{CK}$ will anyway increase the energetic capacity ([ATP]/[ADP] $\left[\mathrm{P}_{\mathrm{i}}\right]$ ratio) of the system.

The final conclusion is that the $\mathrm{Cr}-\mathrm{CrP}$ shuttle provides a high $[\mathrm{CrP}] /[\mathrm{Cr}]$ ratio at rest which is important in order to delay the fast ATP exhaustion at muscle contraction. The partial systems without mitochondrial CK (even those with cytoplasmic CK) are not as effective as the complete one. Therefore, mitochondrial CK expression provides strong amplification of the ATP-buffering capacity.

\section{Acknowledgments}

The author wishes to thank Dr. I.W. Plesner for his concern in this work and fruitful discussions of the results. The work was supported by a basic research grant from the Danish government.

\section{Appendix 1}

The features of the individual enzyme kinetics

\section{'Mitochondrial' pool}

$\mathrm{E}_{1}$ - ATP-producing system:

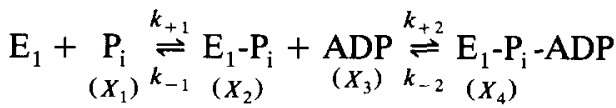

$$
\begin{aligned}
& \stackrel{k_{+3}}{\rightarrow} \mathrm{ATP} \\
& \left(X_{5}\right)
\end{aligned}
$$

$$
\mathrm{E}_{5}-\text { mitochondrial CK: }
$$

$$
\begin{aligned}
& \mathrm{E}_{5}+\underset{\left(X_{5}\right)}{\mathrm{ATP}}+\underset{\left(X_{16}\right)}{\mathrm{Cr}} \stackrel{k_{-14}}{\stackrel{k_{+14}}{\rightleftharpoons}} \mathrm{E}_{5}-\underset{\left(X_{18}\right)}{\mathrm{ATP}}-\mathrm{Cr} \\
& \underset{k_{+15}}{\stackrel{k_{-15}}{\rightleftharpoons}} \mathrm{E}_{5}-\underset{\left(X_{17}\right)}{\mathrm{ADP}}-\mathrm{CrP} \\
& \underset{k_{+13}}{\stackrel{k_{-13}}{\rightleftharpoons}} \mathrm{E}_{5}+\underset{\left(X_{3}\right)}{\mathrm{ADP}}+\underset{\left(X_{15}\right)}{\mathrm{CrP}}
\end{aligned}
$$

'Cytoplasmic' pool

$$
\mathrm{E}_{2} \text { - ATPase: }
$$

$\mathrm{E}_{2}+\underset{\left(X_{6}\right)}{\mathrm{ATP}} \underset{k_{-5}}{\stackrel{k_{+5}}{\rightleftharpoons}} \mathrm{E}_{2}-\mathrm{ATP} \stackrel{k_{6}}{\rightarrow} \mathrm{E}_{2}+\underset{\left(X_{7}\right)}{\mathrm{ADP}}+\underset{\left(X_{10}\right)}{\mathrm{P}_{\mathrm{i}}}$

$\mathrm{E}_{3}-\mathrm{ADP}$-binding subcellular structure:

$$
\mathrm{E}_{3}+\underset{\left(X_{8}\right)}{\mathrm{ADP}} \stackrel{k_{+}}{\stackrel{k_{-7}}{\rightleftharpoons}} \mathrm{E}_{3}-\mathrm{ADP}
$$

$\mathrm{E}_{4}$ - cytoplasmic CK:

$$
\begin{aligned}
& \mathrm{E}_{4}+\underset{\left(X_{6}\right)}{\mathrm{ATP}}+\underset{\left(X_{12}\right)}{\mathrm{Cr}} \underset{k_{-12}}{\stackrel{k_{+12}}{\rightleftharpoons}} \mathrm{E}_{4}-\underset{\left(X_{14}\right)}{\mathrm{ATP}}-\mathrm{Cr} \\
& \underset{k_{+10}}{\stackrel{k_{-10}}{\rightleftharpoons}} \mathrm{E}_{4}-\underset{\left(X_{13}\right)}{\mathrm{ADP}}-\mathrm{CrP} \\
& \underset{k_{+11}}{\stackrel{k_{-11}}{\rightleftharpoons}} \mathrm{E}_{4}+\underset{\left(X_{8}\right)}{\mathrm{ADP}}+\underset{\left(X_{11}\right)}{\mathrm{CrP}}
\end{aligned}
$$

The set of differential equations

Calculations of free $\left[\mathrm{E}_{i}\right]$, denoted as $A_{i}$, using their total concentrations $\mathrm{E}_{\mathrm{o} i}$ and $X_{j}$ :

$A_{1}=\mathrm{E}_{\mathrm{o} 1}-X_{2}-X_{4} ; A_{2}=\mathrm{E}_{\mathrm{o} 2}-X_{7}$;

$A_{3}=\mathrm{E}_{03}-X_{9} ; A_{4}=\mathrm{E}_{04}-X_{13}-X_{14}$;

$A_{5}=\mathrm{E}_{05}-X_{17}-X_{18}$.

Differential equations:

$\frac{\mathrm{d} X_{1}}{\mathrm{~d} t}=-k_{1} A_{1} X_{1}+k_{-1} X_{2}-k_{9} X_{1}+k_{-9} X_{10}$

$\frac{\mathrm{d} X_{2}}{\mathrm{~d} t}=-k_{-1} X_{2}+k_{1} A_{1} X_{1}-k_{2} X_{2} X_{3}+k_{-2} X_{4}$

$\frac{\mathrm{d} X_{3}}{\mathrm{~d} t}=-k_{2} X_{2} X_{3}+k_{-2} X_{4}-k_{8} X_{3}+k_{-8} X_{8}$

$$
-k_{13} A_{5} X_{3} X_{15}+k_{-13} X_{17}
$$

$\frac{\mathrm{d} X_{4}}{\mathrm{~d} t}=-k_{-2} X_{4}+k_{2} X_{2} X_{3}-k_{3} X_{4}$

$\frac{\mathrm{d} X_{5}}{\mathrm{~d} t}=-k_{4} X_{5}+k_{-4} X_{6}-k_{14} A_{5} X_{5} X_{16}$

$\quad+k_{-14} X_{18}+k_{3} X_{4}$
$\frac{\mathrm{d} X_{6}}{\mathrm{~d} t}=-k_{-4} X_{6}+k_{4} X_{5}-k_{5} A_{2} X_{6}+k_{-5} X_{7}$

$$
-k_{12} A_{4} X_{6} X_{12}+k_{-12} X_{14}
$$

$\frac{\mathrm{d} X_{7}}{\mathrm{~d} t}=-k_{-5} X_{7}+k_{5} A_{2} X_{6}-k_{6} X_{7}$

$\frac{\mathrm{d} X_{8}}{\mathrm{~d} t}=-k_{-8} X_{8}+k_{8} X_{3}-k_{7} A_{3} X_{8}+k_{-7} X_{9}$

$$
-k_{11} A_{4} X_{8} X_{11}+k_{--11} X_{13}+k_{6} X_{7}
$$

$\frac{\mathrm{d} X_{9}}{\mathrm{~d} t}=-k_{-7} X_{9}+k_{7} A_{3} X_{8}$ 


$$
\begin{aligned}
& \frac{\mathrm{d} X_{10}}{\mathrm{~d} t}=-k_{-9} X_{10}+k_{9} X_{1}+k_{6} X_{7} \\
& \frac{\mathrm{d} X_{11}}{\mathrm{~d} t}=-k_{11} A_{4} X_{8} X_{11}+k_{-11} X_{13}-k_{-17} X_{11}+k_{17} X_{15} \\
& \frac{\mathrm{d} X_{12}}{\mathrm{~d} t}=-k_{12} A_{4} X_{6} X_{12}+k_{-12} X_{14}-k_{-16} X_{12}+k_{16} X_{16} \\
& \frac{\mathrm{d} X_{13}}{\mathrm{~d} t}=-k_{-11} X_{13}+k_{11} A_{4} X_{8} X_{11}-k_{10} X_{13}+k_{-10} X_{14} \\
& \frac{\mathrm{d} X_{14}}{\mathrm{~d} t}=-k_{-12} X_{14}+k_{12} A_{4} X_{6} X_{12}-k_{-10} X_{14}+k_{10} X_{13} \\
& \frac{\mathrm{d} X_{15}}{\mathrm{~d} t}=-k_{17} X_{15}+k_{-17} X_{11}-k_{13} A_{5} X_{3} X_{15}+k_{-13} X_{17} \\
& \frac{\mathrm{d} X_{16}}{\mathrm{~d} t}=-k_{16} X_{16}+k_{-16} X_{12}-k_{14} A_{5} X_{5} X_{16}+k_{-14} X_{18} \\
& \frac{\mathrm{d} X_{17}}{\mathrm{~d} t}=-k_{-13} X_{17}+k_{13} A_{5} X_{3} X_{15}-k_{15} X_{17}+k_{-15} X_{18} \\
& \frac{\mathrm{d} X_{18}}{\mathrm{~d} t}=-k_{-14} X_{18}+k_{14} A_{5} X_{5} X_{16}-k_{-15} X_{18}+k_{15} X_{17}
\end{aligned}
$$

\section{References}

[1] Bessman, S.P. and Geiger, P.J. (1981) Science 211, 448-452.

[2] Jacobus, W.E. (1985) Annu. Rev. Physiol. 47, 707-725.

[3] Wyss, M., Smeitink, J., Wevers, R.A. and Wallimann, T. (1992) Biochim. Biophys. Acta 1102, 119-166.

[4] Saks, V.A., Vasil'eva, E., Belikova, Yu.O., Kuznetsov, A.V., Lyapina, S., Petrova, L., Perov, N.A. (1993) Biochim. Biophys. Acta $1144,134-148$.

[5] Yoshizaki, K., Watary, H. and Radda, G.K. (1990) Biochim. Biophys. Acta 1051, 144-150.

[6] Shoubridge, E.A., Bland, J.L. and Radda, G.K. (1984) Biochim. Biophys. Acta 805, 72-78.

[7] Shoubridge, E.A. and Radda, G.K. (1984) Biochim. Biophys. Acta 805, 79-88.

[8] Ugurbil, K., Petein, M., Maiden, R., Michurski, S. and From, A.H.L. (1986) Biochemistry 25, 100-107.
[9] Perry, S.B., McAuliffe, J., Balschi, J.A., Hickey, P.R. and Ingwall, J.S. (1988) Biochemistry 27, 2165-2172.

[10] Meyer, R.A., Brown, T.R., Krilovisz, B.L. and Kushmerik, M.J. (1986) Am. J. Physiol. 250, C264-C267.

[11] Meyer, R.A., Sweeney, H.L. and Kushmerik, M.J. (1984) Am. J. Physiol. 246, C365-C377.

[12] Jacobus, W.E. and Diffley, D.M. (1986) J. Biol. Chem. 261, 1657916583.

[13] Barbour, R.L., Ribaudo, J. and Chan, S.H.P. (1984) J. Biol. Chem. $259,8246-8251$.

[14] Saks, V.A., Kuznetsov, A.V., Kupriyanov, V.V., Miceli, M.V. and Jacobus, W.E. (1985) J. Biol. Chem. 260, 7757-7764.

[15] Brooks, S.P.J. and Suelter, C.H. (1987) Arch. Biochem. Biophys. 257, 144-153.

[16] Hall, N., Addis, P. and DeLuca, M. (1979) Biochemistry 18, 17451751.

[17] Fedosov, S.N. and Belousova, L.V. (1989) Biochemistry USSR 54, 39-50.

[18] Lipskaya, T.Yu. and Trofimova, M.E. (1989) Biochem. Int. 18, 1029-1039.

[19] Nihei, T., Noda, L. and Morales, M.F. (1961) J. Biol. Chem. 236, 133-139.

[20] Watts, D.C. (1973) in The Enzymes, 3rd Edn., Vol. 8, pp. 383-455, Academic Press, New York.

[21] Norby, J.G. (1987) Chemica Scripta 27B, 119-129.

[22] Chance, B., Leigh, J.S., Kent, J., McCully, K., Nioka, S., Clark, B.J., Maris, J.M., Graham, T. (1986) Proc. Natl. Acad. Sci. USA 83, 9458-9462

[23] Kenyon, G.L. and Reed, G.H. (1983) Adv. Enzymol. 54, 367-426.

[24] Hammes, G.G. and Hurst, J.K. (1969) Biochemistry 8, 1083-1094.

[25] Barman, T.E., Brun, A. and Travers, F. (1980) Eur. J. Biochem. 110, $397-403$.

[26] Engelborghs, Y., Marsh, A. and Gutfreund, H. (1975) Biochem. J. $151,47-50$.

[27] Quistroff, B., Johansen, L. and Sahlin, K. (1992) Biochem. J. 291, 681-686.

[28] Van Deursen, J., Heerschap, A., Oerlemans, F., Ruitenbeek, W., Jap, P., Ter Laak, H., Wieringa, B. (1993) Cell 74, 621-631.

[29] Marcillat, O., Goldschmidt, D., Eichenberger, D. and Vial, C. (1987) Biochim. Biophys. Acta 890, 233-241.

[30] Schnyder, T., Engel, A., Lustig, A. and Wallimann, T. (1988) J. Biol. Chem. 263, 16954-16962.

[31] Belousova, L.V., Fedosov, S.N., Orlova, E.V. and Stel'mashchuk, V.Ya. (1991) Biochem. Int. 24, 51-58.

[32] Fedosov, S.N. and Belousova, L.V. (1988) Biochemistry USSR 53, $478-491$. 